\title{
A comparative analysis of global Halal certification requirements
}

\begin{abstract}
The aim of this study is to compare the various Halal certification bodies around the world based on the criteria for Halal certification. As the process of awarding Halal certificates varies among the certification bodies, it is pertinent to identify the differences between these selected certification bodies to gauge the gap existing among them. This study will also identify the position of JAKIM, which is the main Halal certification body in Malaysia, among the other main certification bodies around the world. Nine categories were identified in awarding Halal certification to companies. Comparative analysis was then used to see the differences that exist between these certification bodies. The results of the analysis indicate that, based on the nine categories identified, JAKIM is the strictest body in awarding Halal certification to companies.
\end{abstract}

Keyword: Comparative analysis; Certification body; Halal logo; Standards 